\title{
COVID-19 PANDEMIJOS POVEIKIS SERGANČIŲJŲ ODOS NAVIKAIS STACIONARINĖS ONKOLOGINĖS PAGALBOS PRIEINAMUMUI
}

\author{
Vinsas Janušonis ${ }^{1,2}$, Gaivilė Kasap ${ }^{1,2}$, Henrieta Janušonyte் ${ }^{3}$ \\ ${ }^{1}$ Klaipédos universitetas, ${ }^{2}$ Klaipédos universitetiné ligoninè, \\ ${ }^{3}$ Vilniaus universitetas Medicinos fakultetas
}

Raktažodžiai: COVID-19 pandemija, onkologinès pagalbos prieinamumas, odos navikai.

\begin{abstract}
Santrauka
COVID-19 pandemijos metu, palyginus su ikipandeminiu laikotarpiu, buvo sutrikdyta onkologinių ligonių, tarp jų ir sergančiųjų odos navikais, sveikatos priežiūra. Tyrimo tikslas - ištirti ir palyginti pacientų, sergančiu odos navikais, stacionarinès medicinos pagalbos prieinamumą iki COVID-19 pandemijos ir pandemijos metu. Atliekant tyrimą, analizuotos įvairių šalių autorių publikacijos, tirtos odos navikais sirgusių ir hospitalizuotu pacientų ligos istorijos. Straipsnyje atskleisti ịvairūs odos navikais sirgusių pacientų sveikatos priežiūros aspektai ir epidemijos įtaka šių pacientų sveikatos priežiūrai. Nustatyta, kad nors odos navikais sirgusių pacientų medicinos pagalbos prieinamumas epidemijos metu buvo ribotas, tačiau visa medicinos pagalba - planinè ir neatideliotina buvo teikiama.
\end{abstract}

\section{Ivadas}

COVID-19 pandemija sutrikdè sveikatos priežiūrą šalyje, kaip ir visame pasaulyje [1-3]. Nepaisant ekstremaliosios situacijos ir karantino sąlygomis taikytų išimčių, buvo sutrikdyta ir sergančiųjų onkologinėmis ligomis sveikatos priežiūra [4]. Sutriko visas sveikatos priežiūros procesas - profilaktika, diagnostika, gydymas, slauga, reabilitacija $[5,6]$.

Onkologinių pacientų sveikatos priežiūros prieinamumas buvo ribojamas dèl šeimos gydytojų veiklos, ligoninių galimybių, pacientų judejjimo ribojimo bei jų baimès užsikrèsti ir susirgti COVID-19 liga. Onkologiniai pacientai pateko ị aukštos rizikos susirgti COVID-19 liga grupę - jų imuninè sistema dèl ligos bei chemoterapinio, spindulinio gydymo daug silpnesnè. Buvo sutrikdyta ankstyvoji onkologinių ligų diagnostika, didèjo jų užleistumas, vẻlavo, buvo apsunkintas savalaikis gydymas, o kartu ir hospitalizacija, blogéjo gydymo rezultatai [7-9]. Sumažèjo onkologinių pacientų, tarp jų ir sergančiųjų odos vèžiu, vizitų pas gydytojus skaičius, hospitalizacijų skaičius ir gydymo stacionare trukmè $[10,11]$.

Onkologiniai ligoniai, susirgę COVID-19 liga, dažniau patenka ị ligonines bei jos intensyviosios terapijos ir reanimacijos skyrius, dirbtinè plaučių ventiliacija jiems taikoma 3,5 karto dažniau, nei kitiems pocientams [12]. Sergantieji ìvairių lokacijų (tarp jų ir odos) vèžiu, sudare 3,5-3,9 proc. sergančiujų COVID-19 [13,14]. Dèl riboto onkologinès sveikatos priežiūros prieinamumo didès onkologinių ligonių mirtingumo grèsmè ne tik artimiausiais metais, bet ir tolesnèje perspektyvoje [15-17].

Pirmą kartą nustatytų vėžio atvejų skaičius pirmaisiais (2020) Covid-19 pandemijos metais, lyginant su ankstesniaisiais (2019), ženkliai sumažejo. Priežastis - pavèluotas pacientų kreipimais dèl ịvairių su pandemija susijusių priežasčių [18].

Sergančiujų koronaviruso liga tyrimai, atlikti pirmaisiais pandemijos metais, parodè, kad sergančiujų Covid-19 liga ir vėžiu mirštamumas bei mirtingumas didèjo $[19,20]$. Tyrimo duomenimis, penktadalis (20,3 proc.) mirusiųų Italijoje sirgo vėžiu [21]. Daugelyje retrospektyvių tyrimų, Covid-19 liga susirgusių onkologinių pacientų mirštamumas buvo nuo 11,4 proc. iki 35,5 proc. [22]. Galimos tam tikros šių duomenu pataisos, papildomai tiriant nepriklausomus veiksnius (pacientų amžius, lytis, žalingi ịpročiai, bendra sveikatos būklè), galejusius turèti įtakos mirštamumui ir mirtingumui [23-25].

Kai kurie autoriai pažymi, kad 2020 metų Covid-19 pandemijos laikotarpiu sveikatos priežiūros prieinamumas, palyginus su ankstesniais keleriais metais, buvo sutrikęs, tačiau ne iš esmès. Prieinamumą didžia dalimi trikde pacientu, o ne gydymo įstaigų problemos (38 proc. pacientų nesilankè dèl baimès susirgti Covid-19, 18 proc. - dèl transporto problemų ir kt.) [26, 27]. Epidemijos pradžioje COVID-19 liga sergančių onkologinių pacientų mirtingumas buvo keturis kartus didesnis, nei vėžiu nesergančiu [24]. Daugèjo galimai išvengiamų mirčių nuo vèžio [28]. Tai ankstyvosios vèžio diagnostikos ir savalaikio kompleksinio (chirurginio, che- 
moterapinio ir spindulinio) gydymo sutrikimų pasekmè [29].

Teikiant sveikatos priežiūrą pacientams, sergantiems COVID-19 liga ir vėžiu, ypač svarbus prioritetas tenka komandiniam darbui [30]. Šalyje įtakos vėžio gydymui turèjo ir sutrikęs molekulinių-genetikos laboratorijų darbas, kuris buvo perorientuotas ị COVID-19 viruso diagnostiką.

Sergamumas vèžiu ir mirtingumas nuo jo užima vieną pirmujų vietų pasaulyje.

Vèžio diagnostika ir gydymas priklauso daugiadisciplininès komandos kompetencijai (onkologams, chirurgams, radioterapeutams, genetikams ir kt.) bei jų pagalbininkams (psichologams, socialiniams darbuotojams, reabilitologams, atvejo vadybininkams, slaugytojams ir kt.). Sergantieji věžiu dažniau lankosi pas gydytojus, dažniau hospitalizuojami, jiems reikia daugiau įvairių tyrimų, brangių vaistų, tačiau pandemijos metu ambulatorinių vizitu galimybè, hospitalizacijos galimybè ir trukmè, spindulinio gydymo, procedūrų, operacijų skaičius yra ribojami.

Pandemijos sąlygomis sergančiųjų vèžiu sveikatos priežiūrai ypač svarbi ligoninių, kitų sveikatos priežiūros ịstaigu vadovybės veikla, susijusi su sergančiųjų vėžiu COVID-19 infekuotų pacientų sveikatos priežiūros valdymu. Nesant integruoto šios problemos (vèžio ir COVID-19 infekcijos) valdymo nacionaliniu ir, ypač, ligoninių lygmeniu, galimi pražūtingi padariniai [2, 33-35].

Onkologinę pagalbą COVID-19 pandemijos metu reikia iš esmès peržiūrèti - ji turi būti lankstesné, efektyvesnè, tęstinè, naujoviškesnè, greitesnè, atitinkanti pacientų poreikius [36-40]. Būtina perorientuoti ir optimizuoti visos sveikatos priežiūros, ne tik specifinès, teikimą onkologiniams ligoniams epidemijos metu [2, 41-43]. Šios specifinès sveikatos priežiūros perorientavimą būtina vykdyti keičiant ir peržiūrint visą sveikatos priežiūros sistemą, virtualias technologijas COVID-19 pandemijos metu, atsižvelgiant ị pacientu nuomonę bei jų ateitị po pandemijos [2, 44-46].

Tyrimo tikslas - ištirti ir palyginti pacientų, sergančių odos navikais, stacionarinès medicinos pagalbos prieinamumą iki COVID-19 pandemijos ir pandemijos metais.

\section{Tyrimo objektas ir metodika}

Tyrimo objektas - stacionarinès onkologinès pagalbos prieinamumas Klaipėdos universitetinejje ligoninèje. Tyrimas vykdytas $2021 \mathrm{~m}$. sausio-birželio mènesiais.

Tyrimo medžiaga - Klaipèdos universitetinèje ligoninèje 2019-2020 m. gydytų pacientų dẻl piktybinių odos navikų gydymo stacionare ligos istorijos.

Tyrimo metodai - literatūros analizè, statistinè ir lyginamoji analizè. Tyrimui atlikti naudotas autorių parengtas specialus klausimynas (19 pozicijų su 50 galimų atsakymų).

Analizuoti ir lyginti dviejų periodų tyrimo duomenys:
2019 m. (iki COVID-19 pandemijos pradžios) ir 2020 metų. Duomenys analizuoti ir lyginti atsižvelgiant ị amžių, lytị, patekimo ị ligoninę būdą ir kt.

Klaipèdos universitetinèje ligoninèje dèl odos naviku (diagnozių kodai: C 43.0-C 43.9, C 44.0-C 44.9, D 18.01, D 22.1 - D 22.9, D 23.0 D 23.7) $2019 \mathrm{~m}$. buvo stacionarizuoti ir gydèsi 216 unikalių (nesikartojančiais asmens kodais) pacientų (187 dèl piktybinių ir 29 dèl gerybinių navikų). Trijų pacientų, gydytų dèl gerybinių odos navikų, ligos istorijos nerastos, todèl ir netirtos. Kiti pacientai stacionare gydyti pakartotinai.

2020 m. dèl odos navikų ir tais pačiais diagnozių kodais stacionare gydèsi 132 unikalūs (su nesikartojančiais asmens kodais) pacientai (113 dèl piktybinių ir 19 dèl gerybinių navikų). Dviejų pacientų, gydytų dèl gerybinių odos navikų, ligos istorijos netirtos (nerastos).

Iš viso tirtos 418 pacientų ligos istorijos: 238 gydytų 2019 m. ir 180 - 2020 metais. Moteru gydyta 235(56,2 proc.): 2019 m. 140 (58,8 proc.), $2020 \mathrm{~m} .95(52,7$ proc.). 43(10,3 proc.) pacientai gydèsi dèl ịvairių lokalizacijų gerybinių odos auglių - 26(10,9 proc.) 2019 m. ir 17(9,4 proc.) 2020 metais.

380 (90,9 proc.) pacientų stacionarizuoti planine tvarka, iš jų 2019 m. - 213 (89,5 proc.), 2020 m. - 167 (92,8 proc.). Kiti atvyko patys ar buvo pristatyti GMP siuntimu.

Statistinè duomenų analizė atlikta naudojant statistinio duomenų analizès paketo IBM SPSS 23.0 versiją ir MS Excel 2016 programą.

Duomenų skirtumas laikytas statistiškai reikšmingu, kai $\mathrm{p}<0,05$ (statistinio pasikliautinumo lygmuo 95 proc.).

\section{Rezultatai ir jų aptarimas}

2019 m. gydyti stacionare dèl odos navikų pacientai pagal amžių: iki 50 m. - 46(19,3 proc.), per 50 m. - 192 (80,7 proc.). Moterų iki $50 \mathrm{~m}$. gydèsi $27(19,3$ proc.), per 50 m. $-113(80,7$ proc.); vyrų iki $50 \mathrm{~m}$. $-19(19,4$ proc.), per $50 \mathrm{~m} .-79(80,6$ proc.).

$2020 \mathrm{~m}$. gydyti stacionare dèl odos navikų pacientai pagal amžių: iki $50 \mathrm{~m} .-15(8,3$ proc.), per $50 \mathrm{~m}$. - 165(91,7 proc.). Moteru iki $50 \mathrm{~m}$. gydèsi $8(8,4$ proc.), per $50 \mathrm{~m}$. $87(91,6$ proc.). Vyru iki $50 \mathrm{~m}$. gydèsi $7(8,2$ proc.), per 50 m. $-78(91,8$ proc.)

Ikiepideminiu laikotarpiu kreipèsi ir buvo gydoma stacionare daugiau jaunesnio amžiaus pacientu - tiek moterų, tiek vyrų. Tai, kad epideminiu laikotarpiu sumažèjo hospitalizacijos dèl odos navikų skaičius, palyginus su ikiepideminiais metais, atitinka literatūros duomenis $[10,11]$.

Daugiau kaip dviem trečdaliams pacientų 2019 ir 2021 metais odos naviko diagnozė buvo nustatyta 1 mènesio laikotarpiu iki hospitalizacijos (1 lentelè). Statistiškai reikšmingo 
skirtumo (SRS) nenustatyta.

Iš 69 pacientų, kurie kreipèsi vẻliau nei per 1 mènesị ir buvo hospitalizuoti 2019 m., 63 (91,3 proc.) kreipèsi pakartotinai (2020 m. - iš 55 pacientų pakartotinai kreipèsi ir buvo hospitalizuoti $45(81,8$ proc $)$. Statistiškai reikšmingo skirtumo nenustatyta.

2019 m. operuoti 187 (78,6 proc.), 2020 m. - 150 (83,3 proc.) hospitalizuotuc pacientų.

Iš 2019 m. operuotų 187 pacientų $88(47,1$ proc.) taikyta bendroji, regioninè ar spinalinè nejautra, 99(52,9 proc.) vietinè. $2020 \mathrm{~m}$. bendroji, regioninè ar spinalinè nejautra taikyta $18(12,0$ proc.) iš 150 hospitalizuotų operuotu pacientų, vietinė 132(88 proc. pacientų). $2020 \mathrm{~m}$. operacijų metu dažniau taikyta vietinè nejautra, nei 2019 metais (statistiškai reikšmingas skirtumas).

2019 m. 171(91,4 proc.) operacija buvo radikali, 2020 m. tokių operacijų atlikta

1 lentelè. Laikas nuo odos naviko diagnozès nustatymo iki hospitalizavimo.

SRS - statistiškai reikšmingas skirtumas; SNS - statistiškai nereikšmingas skirtumas.

\begin{tabular}{|l|c|c|c|c|c|c|}
\hline \multicolumn{1}{|c|}{ Metai } & \multicolumn{2}{c|}{$\begin{array}{c}2019 \text { m. } \\
\mathbf{n}_{1}=\mathbf{2 3 8}\end{array}$} & \multicolumn{2}{c|}{$\begin{array}{c}\text { 2020 m. } \\
\mathbf{n}_{2}=\mathbf{1 8 0}\end{array}$} & \multicolumn{2}{c|}{$\begin{array}{c}\text { 2019-2020 m. } \\
\mathbf{n}_{1}-\mathbf{n}_{2}\end{array}$} \\
\cline { 2 - 7 } Laikas & abs. sk. & proc. & abs. sk. & proc. & proc. & $\begin{array}{c}\text { statistinio skirtumo } \\
\text { reikšmingumas }\end{array}$ \\
\hline Iki 1 mèn. & 169 & 67,2 & 125 & 69,4 & 2 & SNS \\
\hline Nuo 1 iki 3 mèn. & 11 & 4,6 & 14 & 7,8 & 3,2 & SNS \\
\hline Nuo 3 iki 6 mėn. & 14 & 5,9 & 16 & 8,9 & 3 & SNS \\
\hline Nuo 6 mėn. iki 12 mėn. & 23 & 9,7 & 18 & 10,0 & 0,3 & SNS \\
\hline Daugiau kaip 12 mėn. & 21 & 8,8 & 7 & 3,9 & 4,9 & SNS \\
\hline
\end{tabular}

2 lentelè. Gydymo dèl odos naviko stacionare trukmè.

SRS - statistiškai reikšmingas skirtumas; SNS - statistiškai nereikšmingas skirtumas.

\begin{tabular}{|c|c|c|c|c|c|c|}
\hline \multirow{2}{*}{ Gydymo trukm } & \multicolumn{2}{|c|}{$\begin{array}{l}2019 \mathrm{~m} . \\
n_{1}=238\end{array}$} & \multicolumn{2}{|c|}{$\begin{array}{l}2020 \mathrm{~m} . \\
\mathrm{n}_{2}=180\end{array}$} & \multicolumn{2}{|c|}{$\begin{array}{l}2019-2020 \mathrm{~m} . \\
n_{1}-n_{2}\end{array}$} \\
\hline & abs. sk. & proc. & abs. sk. & proc. & proc. & $\begin{array}{l}\text { statistinio skirtumo } \\
\text { reikšmingumas }\end{array}$ \\
\hline 1 diena & 134 & 56,3 & 111 & 61,6 & $-5,3$ & SRS \\
\hline 2 dienos & 21 & 8,8 & 6 & 3,3 & 5,5 & SRS \\
\hline 3 dienos & 7 & 2,9 & 5 & 2,8 & 0,1 & SNS \\
\hline 4 dienos & 9 & 3,8 & 3 & 1,7 & 2,1 & SNS \\
\hline 5 dienos & 2 & 0,9 & 3 & 1,7 & $-0,8$ & SNS \\
\hline$>5$ dienų & 65 & 27,3 & 52 & 28,9 & $-1,6$ & SNS \\
\hline
\end{tabular}

3 lentelè. Odos naviko lokalizacija.

SRS - statistiškai reikšmingas skirtumas; SNS - statistiškai nereikšmingas skirtumas.

\begin{tabular}{|c|c|c|c|c|c|c|}
\hline \multirow{2}{*}{ Naviko lokalizacija } & \multicolumn{2}{|c|}{$\begin{array}{l}2019 \mathrm{~m} . \\
\mathrm{n}_{1}=238\end{array}$} & \multicolumn{2}{|c|}{$\begin{array}{l}2020 \mathrm{~m} \\
\mathrm{n}_{2}=180\end{array}$} & \multicolumn{2}{|c|}{$\begin{array}{l}2019-2020 \mathrm{~m} . \\
n_{1}-n_{2}\end{array}$} \\
\hline & abs. sk. & proc. & abs. sk. & proc. & proc. & $\begin{array}{l}\text { statistinio skirtumo } \\
\text { reikšmingumas }\end{array}$ \\
\hline Apatinės galūnės & 18 & 7,6 & 22 & 12,2 & $-4,6$ & SNS \\
\hline Viršutinès galūnès & 15 & 6,3 & 9 & 5,0 & 1,3 & SNS \\
\hline Galva & 128 & 53,8 & 96 & 53,3 & 0,5 & SNS \\
\hline Kūnas & 77 & 32,3 & 53 & 29,5 & 2,8 & SNS \\
\hline
\end{tabular}

133(88,7 proc.). Pooperacinių komplikacijų abiem analizuojamais periodais neužregistruota.

Diagnozè nepatvirtinta biopsinès medžiagos tyrimu $2019 \mathrm{~m}$. 6 atvejais $(2,5$ proc.), iš jų penki gerybiniai augliai, vienu atveju pacientas skubiai perkeltas ị kitą ligoninę, nespèta paimti medžiagos, 2020 m. -10 atvejų (5,6 proc., visi augliai gerybiniai).

Gydytojų konsiliumuose dèl gydymo taktikos $2019 \mathrm{~m}$. nagrinèti 154 atvejai (64,7 proc.), 2020 m. 170 atvejų (94,4 proc.). Epidemijos metu gydytojų konsiliumai dèl gydymo taktikos vyko 29,8 proc. dažniau, nei 2019 m. (statistiškai reikšmingas skirtumas).

Dauguma pacientų stacionare buvo gydyti 1 dieną $-2020 \mathrm{~m}$. 5,3 proc. daugiau nei 2019 metais. Dvi dienas gydytų pacientu didesné dalis buvo $2019 \mathrm{~m}$., nei $2020 \mathrm{~m}$. (5,5 proc.) (2 lentelè).

Tai atitinka literatūros duomenis, kad pacientų vidutiné gydymosi trukmé ligoninèse COVID-19 epidemijos metais buvo trumpesnè $[10,11]$.

Abiem nagrinètais periodais daugiau nei pusès odos naviko atvejų lokalizacija buvo galva, antroje vietoje - kūnas, trečioje - apatinès galūnès ir ketvirtoje - viršutinès galūnès (3 lentelè). Statistiškai reikšmingo skirtumo tarp nagrinejjamų periodų nebuvo.

2019 m. 71 pacientas $(29,8$ proc.) hospitalizuotas dèl iki hospitalizacijos epizodo nustatyto naviko diagnozès (kreipèsi pakartotinai). $2020 \mathrm{~m}$. tokių pacientų buvo 48(26,7 proc.).

Pirmą kartą nustatytų odos naviko diagnozių dalis 2020 ir 2019 m. yra panaši. Tai atitinka literatūros duomenis, kuriuose nurodoma, kad epidemijos metais pacientu onkologinių sveikatos priežiūros 
paslaugų prieinamumas buvo šiek tiek sutrikęs [26].

Kartais teigiama, kad hospitalinių atvejų mažejimą pandemijos metu kompensuoja ambulatorinès paslaugos. Klaipédos universitetinèje ligoninejje dèl odos navikų $2020 \mathrm{~m}$. buvo suteiktos 4124 sveikatos priežiūros paslaugos, 2019 m. $-6528(36,8$ proc. daugiau, nei pandeminiais 2020 metais). Tai atitinka literatūros duomenis, kad pandemijos metu ribojama tiek hospitalizacijų galimybè, tiek ambulatorinès pagalbos prieinamumas $[31,32,48]$.

2019 m. 184 pacientai (77,3 proc.) pasirinko gydytoją, 2020 m. -63 (35,0 proc.). COVID-19 epidemijos metais gydytoją pasirinko 42,3 proc. mažiau pacientų, nei 2019 metais (statistiškai reikšmingas skirtumas), nes 2020 m. pacientai turejjo mažiau galimybès ir, gal būt, noro rinktis gydytoją nei 2019 (ikiepideminiais) metais. Šie rezultatai atitinka literatūros duomenis - epidemijos metu ribojamas visos sveikatos priežiūros procesas, kurio dalis yra ir onkologinè priežiūra $[5,6,47]$.

$2020 \mathrm{~m}$. trys pacientai (1,7 proc.) hospitalizuoti dèl odos navikų, persirgę COVID-19 liga.

2019 m. 230 pacientų (96,6 proc.) išrašyti sveikatos būklei pagerèjus, 3(1,3 proc.) - pasveiko (visi gerybiniai augliai), 5(2,1 proc.) mirè (visi dèl pagrindinès ligos - piktybinio odos naviko).

2020 m. 167 pacientai ( 92,8 proc.) išrašyti sveikatos būklei pagerejjus, 7 (3,9 proc.) pasveiko, 6 (3,3 proc.) mirè (visi dèl pagrindinès ligos - piktybinio odos naviko).

Mirštamumo dèl odos navikų 2019 m. ir 2020 m. skirtumas statistiškai nereikšmingas.

\section{Išvados}

Pacientų, sergančių odos navikais, hospitalinis prieinamumas Klaipèdos universitetinèje ligoninejje epideminiais $2020 \mathrm{~m}$. buvo labiau ribotas, palyginus su ikiepideminiais 2019 metais, tačiau visa planinè ir neatidèliotina medicinos pagalba buvo teikiama.

\section{Literatūra}

1. Rosenbaum L. The untold tall-the pandemic's effects on patients without Covid-19. New England Journal of Medicine 2020;382:2368-2371.

https://doi.org/10.1056/NEJMms2009984

2. Janušonis V. Sveikatos priežiūros ir tinkamumo pokyčiai karantino dèl Covid-19 epidemijos metu: pacientų nuomonè ir vertinimas (atvejo analizè). Sveikatos mokslai, 2020;30:72-79. https://doi.org/10.35988/sm-hs.2020.181

3. Saini KS, Las Heras B, Castro J, et al. Effect of the Covid-19 pandemic on cancer treatment and research. Lancet Haematology 2020;7:e432-e435.

https://doi.org/10.1016/S2352-3026(20)30123-X
4. Gosain R, Abdou Y, Singh A, et al. Covid-19 and cancer: a comprehensive review. Current Oncology Reports 2020;22:53-68. https://doi.org/10.1007/s11912-020-00934-7

5. Al-Quteimat OM, Amer AM. The impact of the Covid-19 pandemic on cancer patients. American Journal of Clinical Oncology 2020;43:452-455.

https://doi.org/10.1097/COC.0000000000000712

6. Tsamakis K, Gavriatopoulou M, Schizas D, et al. Oncology during the Covid-19 pandemic: challenges, dilemnas and the pogchosocialimpact on cancer patients. Oncology Letters 2020; 20:441-447.

https://doi.org/10.3892/ol.2020.11599

7. Dinmohamed AG, Visser O, Verhoeven RHA, et al. Fewer cancer diagnoses during the Covid-19 epidemic in the Netherlands. Lancet Oncology 2020;21:750-751. https://doi.org/10.1016/S1470-2045(20)30265-5

8. Sud A, Jones ME, Broggio J, et al. Collateral damage: the impact on outcomes from cancer surgery of the Covid-19 pandemic. Annals of Oncology 2020;31:1065-1074.

https://doi.org/10.1016/j.annonc.2020.05.009

9. Wang H, Zhang L. Risk of Covid-19 for patients with cancer. Lancet Oncology 2020;21:e181. https://doi.org/10.1016/S1470-2045(20)30149-2

10. Lee S, Lim A, Kim MJ, et al. Innovative countermeasures can maintain cancer care continuity during the coronavirus disease - 2019 pandemic in Corea. European Journal of Cancer 2020; 136:69-7.

https://doi.org/10.1016/j.ejca.2020.06.021

11. Al-Shamsi HO, Alhazzani W, Alhuraiji A, et al. A practical approach to the management of cancer patients during the novel coronavirus disease 2019 (Covid-19) pandemic: an international collaborative group. Oncologist 2020. http://www. ncbi.nlm.nih.gov/pubmed/32243668.

https://doi.org/10.1634/theoncologist.2020-0213

12. Liang W, Guan W, Chen R, et al. Cancer patients in SARSCoV-2 infection: a nationwide analysis in China. Lancet Oncology 2020;21:335-337. https://doi.org/10.1016/S1470-2045(20)30096-6

13. Singh AK, Gillies CL, Singh R, et al. Prevalence of comorbidities and their association with mortality in patients with Covid-19: a systematic review and meta-analysis. Diabetes, Obesity and Metabolism 2020.

https://doi.org/10.1111/dom.14124

14. Ofori-Asenso R, Ogundipe O, Agyeman AA, et al. Cancer is associated with severe disease in Covid-19 patients: a systematic review and meta-analysis. Ecancermedicalscience 2020. https://doi.org/10.3332/ecancer.2020.1047

15. Maringe C, Spicer J, Moris M, et al. The impact of the Covid-19 pandemic on cancer deaths due to delays in diagnosis in England, UK: a national, population-based, modelling study. Lancet Oncology 2020;21:1023-1034. 
https://doi.org/10.1016/S1470-2045(20)30388-0

16. Lee LYW, Cazier JB, Starkey T, et al. Covid-19 mortality in patients with cancer on chemotherapy on other anticancer treatments: a prospective cohort study. Lancet 2020; 395: 1919-1926.

https://doi.org/10.1016/S0140-6736(20)31173-9

17. Wolina U. Challenges of Covid-19 pandemic for dermatology. Dermatologic Therapy 2020.

https://doi.org/10.1111/dth.13430

18. Jacob L, Loosen S, Kaldor M, et al. Impact of the Covid-19 pandemic on cancer diagnoses in general and specialized practices in Germany. Cancers 2021; 13:408-418.

https://doi.org/10.3390/cancers 13030408

19. Kuderer NM, Choueiri TK, Shah DP, et al. Clinical impact of Covid-19 on patients with cancer (CCC19): a cohort study. The Lancet 2020;395:1907-1918. https://doi.org/10.1016/S0140-6736(20)31187-9

20. Banerjee A, Pasea L, Harris S, et al. Estimating excess 1-yeear mortality associates with the Covid-19 pandemic according to underlying conditions and age: a population based - cohort study. The Lancet 2020;395:1715-1725.

https://doi.org/10.1016/S0140-6736(20)30854-0

21. Onder G, Rezza G, Brusaferro S. Case-fatality rate and characteristics of patients dying in relation to Covid-19 in Italy. JAMA 2020.

https://doi.org/10.1001/jama.2020.4683

22. Las Heras B, Saini KS, Boyle F, et al. Cancer treatment and research during the Covid-19 pandemic: experience of the first 6 months. Oncology ant Therapy 2020; 8:171-182.

https://doi.org/10.1007/s40487-020-00124-2

23. Warner JL, Rubinstein S, Grivas P, et al. Clinical impact of Covid-19 on patients with cancer: data from the Covid-19 and Cancer Consortium (CCC19). Journal of Clinical Oncology 2020.

https://doi.org/10.1200/JCO.2020.38.18_suppl.LBA110

24. Zhang L, Zhu F, Xie L, et al. Clinical characteristics of Covid-19 - infected cancer patients: a retrospective case study in three hospitals within Wuhan, China. Annals of Oncology 2020; 31:894-901.

https://doi.org/10.1016/j.annonc.2020.03.296

25. Yang K, Sheng Y, Huang C, et al. Clinical characteristics, outcomes, and risk factors mortality in patients with cancer and Covid-19 in Hubei, China: a multicentre, retrospective, cohort study. Lancet Oncology 2020.

https://doi.org/10.1016/S1470-2045(20)30310-7

26. Ququarini E, Saltalamacchia G, Presti D, et al. Impact of Covid-19 outbreak on cancer patient care and treatment: data from an outpatient oncology clinic in Lombardy (Italy). Cancers 2020; 12:2941-2950.

https://doi.org/10.3390/cancers 12102941

27. Dhada S, Stewart D, Cheema E, et al. Cancer services during the Covid-19 pandemic. Systematic review at patients and caregiver's experiences. Cancer Management and Research 2021; 13:5875-5887.

https://doi.org/10.2147/CMAR.S318115

28. Gheorghe A, Maringe C, Spice J, et al. Economic impact of avoidable cancer deaths caused by diagnostic delay during the Covid-19 pandemic: a national population-based modelling study in England, UK. European Journal of Cancer 2021; 152:233-242.

https://doi.org/10.1016/j.ejca.2021.04.019

29. Joode K, Dumoulin DW, Engelen V, et al. Impact of the coronavirus disease 2019 pandemic on cancer treatment: the patients' perspective. European Journal of Cancer 2020;136:132-139. https://doi.org/10.1016/j.ejca.2020.06.019

30. Ngoi N, Lim J, Ow S, et al. A segregated-team model to maintain cancer care during the Covid-19 outbreak at an academic center in Sigapore. Annals of Oncology 2020; 31:840-843.

https://doi.org/10.1016/j.annonc.2020.03.306

31. Haar J, Hoes LR, Coles CE, et al. Caring for patient with cancer in the Covid-19 era. Nature Medicine 2020;26:665-671. https://doi.org/10.1038/s41591-020-0874-8

32. Schrag D, Hershman DL, Basch E. Oncology practice during the Covid-19 pandemic. JAMA 2020;323:2005-2006. https://doi.org/10.1001/jama.2020.6236

33. Jazieh AR. Managing healthcare workers during the Covid-19 pandemic and beyond. Global Journal of Quality and Safety in Healthcare 2020;3:33-35.

https://doi.org/10.36401/JQSH-20-X2

34. Allegra A, Pioggia G, Tonacci A, et al. Cancer and SARSCoV-2 infection: diagnostic and therapeutic challenges. Cancers 2020;12:1581-1588. https://doi.org/10.3390/cancers12061581

35. Mayor S. Covid-19: impact on cancer workforce and delivery of care. Lancet Oncology 2020; 21:633-633. https://doi.org/10.1016/S1470-2045(20)30240-0

36. Jazieh AR, Akbulut H, Curigliano G, et al. Impact of the Covid-19 pandemic on cancer care: a global collaborative study. JCO Global Oncology 2020;6:1428-1438.

https://doi.org/10.1200/GO.20.00351

37. Alhalabi O, Subbiah V. Managing cancer care during the Covid-19 pandemic and beyond. Trends Cancer 2020;6:533-535. https://doi.org/10.1016/j.trecan.2020.04.005

38. Robinson AG, Gyawali B, Evans G. Covid-19 and cancer: Do we really know what we think we know? National Review of Clinical Oncology 2020;17:386-388. https://doi.org/10.1038/s41571-020-0394-y

39. Hoehn RS, Zureikat AH. Cancer disparities in the Covid-19 era. Journal of Surgical Oncology 2020;122:371-372. https://doi.org/10.1002/jso.26043

40. Neal RD, Nekhlyudov L, Wheatstone P, Kocwara B. Cancer 
care during and after pandemic. British Medical Journal 2020;370:m2622.

https://doi.org/10.1136/bmj.m2622

41. Vrdoljak E, Sullivan R, Lawler M. Cancer and coronavirus disease 2019: how do we manage cancer optimally through a public health crisis? European Journal of Cancer 2020;132:98-99. https://doi.org/10.1016/j.ejca.2020.04.001

42. Lai AG, Pasea L, Banerjee A, et al. Estimated impact of the Covid-19 pandemic in people with cancer and excess 1-year mortality in people with cancer and multimorbidity: near realtime data on cancer care, cancer deaths and a population-based cohort study. BMJ Open 2020.

https://doi.org/10.1136/bmjopen-2020-043828

43. Hanne TP, Evans GA, Booth CM. Cancer, Covid-19 and the precautionary principle: prioritizing treatment during a global pandemic. National Review of Clinical Oncology 2020;1:1-3. https://doi.org/10.1038/s41571-020-0362-6

44. Poortmans PM, Guarneri V, Cardoso MJ. Cancer and Covid-19: what do we really know? Lancet 2020;395:1884-1891. https://doi.org/10.1016/S0140-6736(20)31240-X

45. Shumilov E, Hoffknecht P, Koch R, et al. Diagnostic, clinical and post-SARS-CoV-2 scenarios in cancer patients with SARSCoV-2: retrospective analysis in three German cancer centers. Cancers 2021;13:2917-2927. https://doi.org/10.3390/cancers13122917

46. Rogado J, Obispo B, Pangua C, et al. Covid-19 transmission, outcome and associated risk factors in cancer patients at the first month of the pandemic in a Spanish hospital in Madrid. Clinical and Translational Oncology 2020. https://doi.org/10.1007/s12094-020-02381-z

47. Bhattacharjee A, Vishwakarme GK, Banerjee S, Shukla S. Disease progression of cancer patients during Covid-19 pandemic: a comprehensive analytical strategy by time - dependent modelling. BMC Medical Research Methodology 2020; 20:209-216. https://doi.org/10.1186/s12874-020-01090-z

48. Zhang $\mathrm{H}$, Han $\mathrm{H}, \mathrm{He} \mathrm{T}$, et al. Clinical characteristics and outcomes of Covid-19 infected cancer patients: a systematic review and meta-analysis. Journal of the National Cancer Institute 2020.

\section{INFLUENCE OF COVID-19 PANDEMIC ON THE AVAILABILITY OF INPATIENT ONCOLOGY CARE FOR PATIENTS WITH SKIN TUMORS

\author{
V. Janušonis, G. Kasap, H. Janušonytė
}

Keywords: Covid-19 pandemic, availability of oncology care, skin tumors.

Summary

During the Covid-19 pandemic, health care for oncology patients, including those with skin tumors, was disrupted compared to the prepandemic period.

The aim of this article - to study and compare the availability of inpatient care for patients with skin tumors before and during Covid-19 pandemic.

Material and methods. From January to June 2021 the survey has been performed. The study used the medical histories of 418 patients treated in 2019-2020. The research data were analyzed and compared in two periods - 2019 and 2020 by age, gender, method of hospitalization, etc.

Analysis of statistical date was done using the software SPSS version 23.

Results. In both analyzed periods, the absolute majority of women over 50 years of age were treated in hospital.

More Than two - thirds of patients were hospitalized within one month of being diagnosed with skin tumor.

80,6 percent of hospitalized patients underwent surgery, all patients were diagnosed histologically.

More than half of the skin tumors are localized to the head. More than two - thirds of treated patients were diagnosed with a skin tumor for the first time.

2,6 percent treated patients died of a skin tumor, others discharged from the hospital after recovery or recovery.

Conclusions. The availability of hospital treatment for patients with skin tumors in a pandemic 2020 was somewhat limited compared to 2019. However, all medical care, both scheduled and emergency, was provided.

Correspondence to: janusonis@kul.lt

Gauta 2021-10-01 